\title{
Sugerencias al neoliberalismo: haga su autocrítica
}

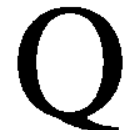
uienes hemos recorrido unas cuantas décadas entre capitalismo y socialismos reales nos permilimos, al finalizar el siglo, plantear una interrogante: ¿por qué estos dos sistemas, opuestos en tantos aspectos, coinciden históricamente en un rasgo común, el rechazo a la autocrítica? - La teoría de la coexistencia pacífica, editada por Lenín y oficializada por Stalin en Europa del Este, inspira en el adagio romano: si vis pacem, para bellum: si quieres la paz, prepara la guerra. El capitalismo aparece como el enemigo irreconciliable y la amenaza de la guerra como el complemento posible de las negociaciones políticas. La teoria de la coexistencia pacífica presenta la misma lectura desde el paralelo capitalista y de ahí emanan las dos carreras competitivas: la disputa por el crecimiento económico (milagros económicos) y la desgastante carrera armamentista. La mutua crítica transciende las páginas de los textos oficiales (textos para la exportación) y alcanza el elevado derroche de un millón de dólares por minuto en producción bélica, en 1970, y los casi dos millones en 1987. Superabunda la mutua crítica agresiva, que ciega toda oportunidad para la propia autocrítica.

Cuando en la década de los sesenta, en razón de las respectivas reformas económicas en el Este y Oeste europeos, surgen las "teorías de la convergencia", estos autores fueron vistos como ilusionistas en un lado, y como peligrosos revisionistas en el otro bando. Se afianza el dogma de que ambos sistemas son irreconciliables, que no pueden tolerar reformas sustanciales y, por lo tanto, no hay espacio histórico para ninguna tercera vía. Esta postura se afianza con la desintegración de los socialismos reales luego de 1989 y 1991.

Este radicalismo entre opuestos coexiste con cierto ablandamiento de aristas y cierta dosis de aulocrítica debido a la aparición de tanlos "NEOS": neo-clásicos, neo-liberales, neo-keynesianos, neo-socialistas, neo-estructuralistas... Hay varias lecturas posibles sobre estas reencamaciones. Es claro que a todos nos cuesta desprendemos de nuestro ásbol-ideológico. Tal vez existe en cada grupo alguna 
aceptación de los errores cometidos, pero es más fuerte la convicción de que dicho modelo o sistema enciena la respuesta a los desafíos del nuevo entomo mundial. En consecuencia, el prefijo "neo" no significa algo nuevo, sino más de lo mismo. Tal parece ser el caso del actual neo-liberalismo. No queda nada claro que la presencia de tantos "neos" nos esté llevando a un proceso de sustancial autocrítica, que imprima un nuevo rumbo al tercer milenio.

Simplificando la variedad de colores y modelos intermedios, que por cierto son muy reales, analizo primero la crisis de la autocrítica en los llamados "socialismos-reales", dedicando un espacio mayor a la crisis de autocrítica en el modelo imperante de la globalización, con una aplicación a nuestros principios filosóficos y postulados económicos editados en la presente década.

\section{En Europa del Este la autocrítica llegó tarde}

Hemos escuchado y comentado la diversidad de causas y razones que desembocaron en la descomposición política y desintegración económica de los socialismos-reales. Cada autor, desde su propia disciplina o desde su credo ideológico, enfatiza más unos u otros motivos, y no faltan quienes fueron sorprendidos por los hechos consumados. Como no se trata de narrar la historia, sino de interpretarla, una lectura razonada permite hacer esla afirmación: década tras década los dirigentes de estos Estados, es decir sus nomenklaturas, se opusieron a escuchar y más a aceptar las críticas que emanaban desde otros modelos, incluso socialistas, y persiguieron física y políticamente los brotes de autocrítica que emanaban desde el interior y con la sana intención de salvar al modelo. En esta parte me ahorro las citas de documentos y autores que aparecen en nuestras revistas ECA y Realidad Económica Social, ciñéndome a algunos hechos más relevantes.

\subsection{La autocrítica sofocada}

Desde 1919 se lanza el primer boomerang contra las otras vías o altemativas sociales y socialistas, calificándolas como "social-traidores". Utilizo el término boomerang porque en el foro de La Sorbona (París, 1990) los "acusados" (socialdemocracia y otros) devuelven la misma acusación a los supervivientes de la ortodoxia de los socialismos-reales. Desde la década de 1920, como se recordó antes, la teoría de la coexistencia pacífica oficializa la doctrina del capitalismo como enemigo irreconciliable y de la guerra como una amenaza latente en el proceso de negociaciones. Como de hecho hay una coexistencia y cada vez más una necesidad de sostener relaciones comerciales intemacionales, se plantea el dilema del "kolo-kogo" (expresión condensada rusa), ¿quién a quién?: cómo mantener los necesarios intercambios comerciales, exportaciones e importaciones, 
sin que ello signifique un contagio de principios administrativos ajenos al sistema.

Este desafío del "kolo-kogo" (¿quién vencerá a quién?) se traducirá en la aplicación de la teoría de la coexistencia pacífica a los países satélites integrados al bloque: el principio de la "soberanía limitada" los somete a la hegemonía de la nación que llevó a cabo la revolución mundial. La aplicación de este principio legitimó la invasión a Hungría (1955) y el aniquilamiento de la Primavera de Praga (Checoslovaquia,1968)... Estos ejemplos muestran el rechazo a la autocrítica emergente desde el interior del bloque. Toma fuerza el dogma de la posesión de la verdad, de la única respuesta histórica o del fin de la historia.

La fuerza del dogma se asienta en el todo poder, el todo saber, el todo imponer, y cada vez menos en los hechos que refutan el dogma. Cuando el dogma deja de ser verdad sólo queda la publicidad y la fuerza para sustentarlo. En expresión de Ola Sick, inspirador de la Primavera de Praga, "contra la fuerza bruta sólo queda armarse de paciencia". Las propuestas de hacer "perestroika", reestructuración económica, se han topado secuencialmente con el rechazo a la autocrítica, incluido el último intento de M. Gorbachov (1987), quien integró la perestroika con la glasnot (decir la verdad) y la novoye mislenhiye, nuevas ideas para mi país y el mundo. Fue el último y fallido esfuerzo por instaurar la autocrítica; ahora Rusia se enfrenta con un futuro impredecible.

\subsection{La errada crítica capitalista}

Desde el lado capitalista, la crílica ubica el principio del mal en la planificación económica estatal. En realidad y verdad, al entomo histórico de una Europa, oriental y occidental, destruida por dos guerras mundiales y sumida en el desconcierto de la gran crisis del liberalismo económico, las técnicas de planificación, los planes pronósticos y quinquenales, los avances en la contabilidad nacional, explican que en ambos lados del telón de acero se lograra una rápida reconstrucción de la infraestructura física, las mayores lasas de crecimiento sostenido, sustentadas en la inversión productiva del factor trabajo. La diferencia radical está en el modo de gerenciar la planificación.

En Europa occidental, la planificación se concibe como un ejercicio concertado y participado entre la administración pública y los representantes, empresariales y laborales, de los sectores productivos; se enfatiza la inversión intensiva o aplicación de las nuevas tecnologías a la producción civil, el desarrollo armónico geográfico y, pasado un tiempo de austeridad consumista, la atención a la demanda final. Se hablará de economía mixta, concertada y de Estado social de bienestar. Surge también la economía social de mercado en Alemania occidental.

En Europa del Este, de acuerdo con el modelo soviético, la planificación se convierte en el instrumento macroeconómico para la concentración del poder, 
logrando una plena simbiosis del poder político y económico, sometido éste último al dictamen de la cúspide política (art. 6 de la Constitución soviética), sin resquicio para ninguna crítica o autocrítica. Podemos hablar de planificación militarizada en un doble sentido: planificación central, verticalista y autoritaria de los menores detalles o índices de producción; el balance monetario que las empresas reciben del Gosbank (banco de Estado) sirve para la ejecución y control del balance de producción remitido por el Gosplan o plan de Estado. Planificación militarizada en el orden político por cuanto la producción bélica y la carrera espacial absorben los mejores recursos del presupuesto, en fondos y científicos, quedando relegada la producción civil al "principio del residuo", en expresión de M. Gorbachov y A. Aganbegian. En los socialismos reales, la jerarquía militar y la aristocracia de los sectores bélico-espacial se integran con la élite del partido en el triunvirato o nomenklatura todopoderosa.

\section{La autocrítica es silenciada}

También en el área de la planeación económica se bloquea todo proceso de aulocrítica, nacido de economislas teóricos y práclicos. Quienes hayan seguido la ajetreada historia soviética recordarán cómo fueron físicamentre eliminados destacados líderes políticos como N. Bukharin y E. Preobrazhensky (La Nueva Economía), y deportados connolados economistas como N. Kondratief, Groman, Bazarov... en las purgas de 1930. Se calificó de revisionismo impertinente el modelo semicompetitivo ( socialismo de mercado), elaborado en Europa occidental por un conjunto de economistas, entre ellos Oscar Lange, destacado economista socialista polaco. Este modelo presentaba una integración aplicada de la teoría macro y microeconómica al proceso de la planificación. Se acusará y amenazará políticamente, en la década de los cuarenta, a un conjunto de ingenieros proyectistas y economistas industriales, quienes recomendaban aplicar las normas más elementales del cálculo económico en el diseño y seleción de inversiones y en la fijación de los precios. Entre ellos, el Premio-Nobel L. Kantorovich, iniciador de la programación lineal.

Aprobada oficialmente la Ilamada "reforma Liberman" (1965), no quedan rastros significativos de ella para 1970 y su protagonista muerc en 1983 alone and forgotten. Con el advenimiento de la Perestroika (1987) y las perspectivas de aires nuevos también se van engavetando los sucesivos programas de reforma económica, desde el plan de los $\mathbf{5 0 0}$ días de S. Sathalin hasta el plan Yaulinsky, de 1991. Cuando el Fondo Monetario Internacional y el Banco Mundial se aprestaban a firmar el plan Yaulinsky, ya no existe la URSS (decreto de Minsk; diciembre de 1991) y toda la "unión" se ve reducida a una débil Comunidad de Estados Independientes (CEI). Este concentrado recital de propuestas, razonadas y racionales, al sistema central de planificación muestra que el rasgo distintivo de los socialismos reales fue el rechazo de toda autocrítica del modelo autoritario, 
de ordeno y mando, de la gestión económica.

\subsection{Nuestro pasado es imprevisible}

Tampoco había lugar para criticar la propia historia intema, adomada y retocada por la omnipresente publicidad. Un testimonio elocuente es el Jacónico refrán popular ruso: "nuestro pasado es imprevisible". Con ocasión de la Mesa Redonda de Historiadores Soviéticos (1988), la Academia de Ciencias de la URSS publica quince volúmenes donde historiadores y sociólogos, también los juristas, realizan un proceso de arqueología histórica en búsqueda de la verdad (glasnot) oculta y ocultada en los textos de exportación. La autocrítica más objetiva y radical se realiza, luego de la aparición de la Perestroika, en los foros internacionales de Barcelona (España,1988), el foro de Moscú, en 1989, y el foro de La Sorbona, París, en 1990). En Europa tuvo gran resonancia la carta de S. Sathalin, escrita al momento del golpe a M. Gorbachov, 1991, y la postdata del mismo Gorbachov sobre la verdad y las consecuencias del fallido golpe (1992). Pero esta autocrítica llega tarde y ahora la escuchamos como el canto del cisne.

Afirmar que el rasgo típico de los socialismos reales fue el perenne rechazo a la crítica y autocrítica del sistema y del modelo concreto equivale a decir, en otras palabras, que profesaron el dogma de la única verdad, a cualquier precio y, en consecuencia, se instalaron en un centralismo institucionalizado. Una lección del siglo $\mathrm{XX}$, desde su primera hasta su última década, es que ya no se aceptan los imperios centralistas, coloniales o estatistas. Los socialismos reales han aprendido - a su costa - esta lección, que todavía es verdadera para los nuevos imperialismos. Los foros antes citados se centran en este problema: la intolerancia del centralismo o el imperio se hace la perestroika.

\subsection{Del centralismo a las fuerzas centrífugas}

El centralismo prolongado genera necesariamente crecientes fuerzas centrífugas; en Europa del Este aparecieron a modo de temblor, en la década de 1950, y como lerremoto luego de 1989. Si el pasado fue imprevisible, ahora el futuro se vuelve impredecible. P. Kennedy resume la triple crisis en un breve párrafo: "Una crisis de legitimidad política del sistema soviético ha interactuado con una crisis de la producción económica y el abastecimiento social, y ambas se han visto exacerbadas por una crisis de relaciones étnicas y culturales". Por ello, la caída de los socialismos reales puede describirse como descomposición política y desinlegración económica. De ello sacamos una gran lección: el rechazo de la autocrítica es el fin de la propia historia.

Por eso la historia del siglo XX no termina; luego de la caída del muro de 
Berlín se levantan otros muros. Ahora es el capitalismo en su versión neoliberal quien levanta un sólido muro a la crítica y, por supuesto, a la propia autocrítica. El dogma actual se refuerza porque la victoria ha terminado con la misma crítica. Nos resistimos a esta victoria y nos preguntamos cómo será el siglo XXI.

\section{El siglo XXI, ¿será otro siglo XX?}

Si Lester Thurow y Juan Pablo II nos invitan a mirar hacia el siglo XXI y al tercer milenio, parecería que volver la cabeza hacia el siglo $\mathrm{XX}$ es nadar contracorriente. Tal vez nos dé miedo hacer este regreso porque el siglo $\mathrm{XX}$ ha sido, en palabras de Isaiah Berlin, "el más terrible de la historia de Occidente". Igual de contundente es el juicio del músico Yehudi Menuhin: "despertó las mayores esperanzas que concibió la humanidad y destruyó todas las ilusiones e ideales". Desaparecidos, de momento, regímenes totalitarios (nacional-socialismo, comunismo), la doctrina triunfalista del fin de la historia enuncia "la universalización de la democracia liberal occidental como forma final de gobierno humano".

\section{1. ¿Tiene futuro la democracia?}

Arthur Schlesinger, asesor del presidente John F. Kennedy, se pregunta: “¿No acompañó la misma deslumbrante esperanza la transición del siglo XIX al XX? Estos cien años tan terribles de la historia de Occidente comenzaron con una atmósfera de optimismo y exaltadas expectativas. La gente de buena voluntad en 1900 creía en la inevitabilidad de la democracia, en la invencibilidad del progreso, la decencia de la naturaleza humana y el advenimiento de un reino de razón y paz"1. Las dos guerras mundiales, la gran crisis económica de los años treinta, el advenimiento de regímenes totalitarios, pusieron fin a toda esperanza, y "en 1941 sólo una docena de democracias subsistían en el planeta".

Esta triste historia da pie a A. Schlesinger para hacer la siguiente reflexión: "Los fracasos políticos, económicos y morales de la democracia habían entregado la iniciativa al tolalitarismo. Algo semejante podría ocurrir de nuevo. Si la democracia liberal fracasara en el siglo XXI, como fracasó en el siglo XX, en la construcción de un mundo humanitario, próspero y pacífico, invitará a que asciendan credos alternativos que tenderían a basarse, como el fascismo y el comunismo, en la renuncia a la libertad y la entrega a la autoridad"2.

Si al final del siglo XIX había optimismo y esperanza de un nuevo mundo de razón y paz, es porque también había desesperanza y rechazo del desorden económico y de la desigualdad social, emanadas de la democracia del laissezfaire. La esperanza y la desesperanza se entremezclan en la Rerum Novarum de León XIII y los hechos nuevos y tristes que se presagiaban eran la cosecha 
sembrada por el modelo imperante. Un fin de siglo no corta la historia en dos: también el liberalismo de mercado del siglo XIX se proclamó como el fin de la historia, ajeno a toda autocrítica, hasta que las perturbaciones bélicas, económicas, políticas y sociales se alzaran como dura crítica histórica. Lo anterior no significa que los inicios del siglo XXI deban ser una repetición del siglo XX, pero sí es cierto que al finalizar el presente siglo enfrentamos una renovación de similares y aún mayores desafíos sociales que marcaron el final del siglo XIX.

\subsection{La ley de la aceleración}

A. Schlesinger habla de una ley de la aceleración. "Hoy, la aventura democrática debe hacer frente a tremendas energías reprimidas que amenazan con lanzarla fuera de su rumbo e incluso precipitarla contra las rocas... La democracia por sí misma es la secuela política de la tecnología y del capilalismo, las dos fuerzas más dinámicas, es decir, deseslabilizadoras, que operan en el mundo de hoy"3. Con otras expresiones, la ley de la aceleración nos arrastra contra las rocas que anunciara la cumbre de Copenhague: se desarrolla la pobreza, el crecimiento con desempleo y la insolidaridad social. Vuelven a emerger dos fenómenos del siglo XIX: la proletarización y el darwinismo social, con la creciente exclusión del trabajo.

A. Schlesinger condensa estos efectos en dos breves párrafos. "La ley de la aceleración nos precipita ahora en una nueva edad. El paso de una economía basada en la industria a otra basada en el ordenador es más traumática que el paso de nuestros bisabuelos desde una economía basada en la agricultura a otra basada en la industria. La revolución industrial se extendió sobre generaciones y dio tiempo a reajustes humanos e institucionales. La revolución informática es mucho más rápida, más concentrada y más drástica en su impacto.

El mundo informatizado plantea problemas a la democracia. Mientras la revolución industrial creó más puestos de trabajo de los que destruyó, la revolución informática amenaza con destruir más puestos de los que crea. Amenaza también con levantar nuevas y rígidas barreras de clase, especialmente entre los instruidos y no instruidos. La desigualdad económica ha aumentando ya en los Estados Unidos hasta el punto de que son mayores las disparidades en el igualitario Estados Unidos que en las sociedades clasistas de Europa. Felix Rohatyn, banquero de inversiones que rescaló de la bancartota a la ciudad de Nueva York, habla de las tremendas transferencias de riqueza desde los trabajadores de baja capacitación y clase media a los propietarios de los bienes de capital y a la nueva aristocracia tecnológica"4.

Estas breves citas de A. Schlesinger vienen a confirmar la exposición de Frank Hinkelammert en su artículo: "El huracán de la globalización". Hinkelammert presenta al primer mundo de hoy como un archipiélago que aparece en 
todos lados, en el interior de un mar circundante de espacios que ya no pueden integrarse ni económica ni socialmente. Los enclaves de este archipiélago (las inversiones altamente tecnificadas) conservan un dinamismo hacia dentro y una exclusión de otras inversiones productivas hacia fuera. Se trata de una relación de exclusión: "hoy día se habla de un tercer mundo al interior del primer mundo y de un primer mundo en el tercero". Tratamos de resumir este análisis de Hinkelammmert en un artículo, donde a la exclusión del trabajo generada por la revolución tecnológica se surnan, en nuestro país, los fenómenos de la estanflación, el deterioro ecológico, el crecimiento con desempleo y desigualdad, la terciarización económica fomentada por el oligopolio bancario, el sensible rezago tecnológico y el sesgo hacia la inversión especulativa-financiera5.

\subsection{El capitalismo agrega nuevos problemas}

El análisis de A. Schlesinger sustenta las aplicaciones sugeridas en dicho artículo, porque a los efectos excluyentes de la revolución tecnológica se suman las consecuencias políticas, económicas y sociales de un capitalismo que es globalización. "Aunque el desarrollo de la tecnologia crea nuevos e importantes problemas y augura una revisión del sistema político por medio del cual los tratamos, la embestida del capitalismo puede tener consecuencias incluso más perjudiciales. Hay que comprender la relación existente enlre capitalismo y democracia...

...El capitalismo ha demostrado ser el motor supremo de la innovación, la producción y la distribución. Pero su método, mientras va dando bandazos hacia adelante, sin atender apenas otra cosa que su propio beneficio, es lo que Joseph Schumpeter llamaba "destruccción creativa". En su teoría económica, el capitalismo descansa sobre el concepto de equilibrio. En la práctica, sus propias virtudes lo arrastran hacia el desequilibrio. Este es el dilema del conservadurismo contemporáneo. El mercado sin restriccciones, que adoran los conservadores, mina los valores -estabilidad, moralidad, familia, comunidad, trabajo, disciplina, gratificación demorada - que propugnan los mismos conservadores. El resplandor del mercado, la codicia, el "a corto-placismo", la explotación de apetitos lascivos, la facilidad del fraude, la ética del ventajismo..., todo ello está en conflicto con los pretendidos ideales conservadores. Un "capitalismo estacionario" es una contradicción en sus términos"6.

Ls densas líneas de este asesor del presidente J. F. Kennedy me traen a la memoria expresiones similares del arzobispo de París, Mons. Jean Marie Lustiger, en entrevista que le hiciera la revista Idées, en marzo de 1996. “¿Por qué juzga usted tan severamente a la sociedad liberal?" Miremos nuestra civilización. Da la prioridad a los valores financieros y somete a dichos valores toda la cultura: las costumbres, la vida familiar y las eslructuras elementales de la sociedad. El 
individuo es considerado fundamentalmente como un agente de la vida económica. Toda su formación busca responder a los imperativos de la máquina, producir y ganar. Quienes logran el éxito peligran convertirse en robots vivientes, y no sabrán cómo educar a sus hijos. Si esta costumbre se extiende, se dejarán comprar como lo más natural. Qué destrucción del equilibrio humano y qué consecuencias. De nuevo, zonas enteras de la sociedad se están proletarizando y sus hijos queman los supermercados. Una sociedad puede destruirse en pocos años; para reconstruirla harán falta algunas generaciones.

Se ha adoplado la psicología del financista. Si se busca el beneficio inmediato es seguro que se pone en peligro el largo plazo. La valoración financiera sustituye a los proyectos industriales y a los flujos destinados a la producción. La gestión financiera de las empresas puede llevar a preferir el beneficio más inmediato o de mayor riesgo, sin miras a la realidad circundante. ¡Cuántos males nos hubiéramos ahorrado si se hubiera evitado la proletarización del siglo XIX! Al decir esto no se critica la aclividad económica, ni la libertad empresarial. Se trata de comprender la evolución de nuestra sociedad... La moneda es un símbolo abstracto, ella cuantifica toda la realidad, se otorga un precio. La moneda es una especie de álgebra de la actividad humana, reducida a la medida de la unidad monetaria... La bolsa mundial funciona mejor que las Naciones Unidas. Los financieros anticipan la evolución de la humanidad. Pero, ies a ellos a quienes corresponde conducirla? y, ¿a beneficio de quién??

Esta última frase del arzobispo de París encaja con el siguiente párrafo de A. Schlesinger: "Incluso los capitalistas de primera fila se sienten abrumados por lo que ha traído consigo el capitalismo salvaje. Si la comprensión del capitalismo se puede medir por el éxito en obtener dinero de él, nadie comprende mejor el capitalismo contemporáneo que el financiero y filántropo George Soros. "Aunque he hecho una fortuna en los mercados financieros - escribe Soros temo ahora que la intensificación sin trabas del capitalismo de laissez-faire y la difusión de los valores de mercado en todas las áreas de la vida está poniendo en peligro nuestra sociedad abierta y democrática. La persecución sin inhibiciones del interés propio — continúa Soros- produce desigualdades e inestabilidad intolerables"8.

El capitalismo neoliberal de finales de siglo acumula una secuencia de efeclos perversos: la revolución intensiva de alta tecnología genera alrededor un estancamiento dinámico o exclusión del trabajo, brevemente indicada por $\mathbf{A}$. Schlesinger y desarrollada con más detalle por F. Hinkelammert. Mientras que el eje central de la teoría económica es el equilibrio, la situación real son los desequilibrios estructurales. Por encima del poderoso mercado de la producción se sitúa el imperio del mercado financiero, que impone sus políticas a los Estados y al sector real de la economía. "En cuatro días de transferencias bancarias internacionales, resultado de las transacciones de divisas, se manipula más dinero que toda la producción creada por la economía de Estados Unidos en un año, o 
por la economía mundial en un mes". La especulación financiera genera una inestabilidad monetaria e imprime lentitud al crecimiento económico... Esta inestabilidad favorece al capital especulativo de tal manera que hoy las tasas de beneficio de las instituciones bancarias (resultado del comercio de divisas) son las tasas de beneficio más altas de todas las actividades empresariales del mundo". (ECA,1997; p. 806)

\subsection{La devaluación de los valores nacionales}

Este desquiciamiento de los valores humanos, simultáneamente señalado por A. Schlesinger, G. Soros y el arzobispo de París, ha sido analizado, a nivel de nuestro continente, en el informe presentado por los dieciocho superiores provinciales de la Compañía de Jesús, "El neoliberalismo en América Latina" (México, noviembre-1996). Este documento ha sido publicado en la revista Realidad (1996, No 54) y posteriormente comentado en la revista ECA. Muy similares son las conclusiones emanadas del sínodo de los obispos de Norte y Latinoamérica, reunidos en Roma en noviembre de 19979. Al huracán de la globalización financiera y mercantil se suman los oligopolios de los medios de comunicación social, que imprimen - día tras día - en las mentes y conciencias nuevas pautas de comportamiento, carentes de ética y solidaridad, agotando atros valores tradicionales. Se está llevando a cabo un lavado de conciencias y sus efeclos serán perniciosos en el próximo futuro.

Con la pérdida de valores y el abatimiento de las fronteras, la globalización extermina la misma identidad nacional. "Un objetivo de la creatividad capitalista es la economía globalizada. Un candidato - no previsto- para la destrucción capitalista es el Estado nacional, tradicional asiento de la democracia. El ordenador convierte el mercado sin trabas en un monstruo global irresistible, que atraviesa las fronteras, debilita los poderes nacionales de implementación de impuestos y regulaciones, impide la gestión nacional de las tasas de interés e intercambio, amplía las disparidades de riqueza lo mismo dentro de las naciones que entre ellas, derrumba las nomas laborales, degrada el medio ambiente, niega a las naciones el poder de dar forma a su propio destino económico, sin dar cuenta a nadie y crea una economía mundial sin una política mundial. El ciberespacio está más allá del control nacional. No existen autoridades que proporcionten control internacional. ¿Dónde está ahora la democracia?"10.

A. Schlesinger resume en este párrafo unas acertadas pinceladas del proceso de desnacionalización, subrayando un aspecto del imperio neoliberal: la ausencia de autoridades que proporcionen un control internacional. Como decía el arzobispo de París, la bolsa mundial funciona mejor (tiene más poder) que las Naciones Unidas. Aquí emerge un rasgo que emparenta al capitalismo con los socialismosreales: el centralismo omnipresente, que también puede generar violentas fuerzas 
centrífugas. De acuerdo con Hinkelammmert, estas fuerzas no nacen espontáneamente de los propios Estados; ausencia de intervenciones estatales no significa ausencia del Estado. "La globalización no es posible sin una acción constante y decidida de los Estados. Ahora, los Estados funcionan, sobre todo, como instancias de la globalización que debe facilitar los flujos de mercancías y capitales y fomentarlos con subvenciones inmensas, que en tamaño superan la cantidad de subvenciones que el Estado social jamás haya efectuado" (ECA, 1997, p. 804).

Sin embargo, la globalización tiene que enfrentar la tensión entre integración y desintegración. En 1991 se firma el decreto de Minsk, por el cual y con el beneplácilo de los mismos rusos, se pone fin a la Unión Soviética; esta desintegración se presiente en el foro de La Sorbona (París, 1990). Uno de los hechos y temores que se cemía sobre los países del Este europeo era el surgimiento de las nacionalidades y de los nacionalismos, como una respuesta natural al prolongado centralismo. El término "Partido", símbolo del centralismo, engendra miedo y rechazo de la acumulación del poder. Pero, junto con los aspectos positivos de la recuperación de valores nacionales y de organizaciones cívicas populares (Solidaridad, Forum, Alianza Democrática, Unión Democrática...), aparecen también los rasgos adversos de la xenofobia y de los fundamentalismos religiosos, que derivan en crueles guenas civiles.

Este fenómeno de la desintegración se expande hoy día a nivel mundial, en parte debido a la misma globalización que ha generado cuatro mundos: la presencia de un tercer mundo en el interior del primer mundo y de un primer mundo en el tercer mundo. Al mismo tiempo crecen las protestas contra las discriminaciones étnico-raciales, nuevos inmigrantes, disparidades de género y se recrudecen los fundamentalismos religiosos. Mientras que la globalización nos dibuja un sólo mercado circundante, en realidad el mundo es un mosaico de nacionalidades y en el interior de cada nación se renuevan las feudos insolidarios.

\subsection{Reflexiones y profecías}

A. Schlesinger concluye su comentario con una serie de reflexiones proféticas, de las que extractamos las más afines a nuestro tema. "El mundo de hoy está desgarrado en direcciones opuestas. La globalización ocupa el puesto de mando y dirige a la humanidad, pero -al mismo tiempo- impulsa a las personas a buscar refugio frente a sus poderosas fuerzas, que están más allá de su conlrol y comprensión. Se retiran a unidades familiares, inteligibles, protectoras. Ansían la política de la identidad. Cuanto más rápidamente se integra el mundo, más personas se refugiarán en sus enclaves religiosos, étnicos o tribales. La integración y la desintegración se alimentan mútuamente".

Junto con esta conducla de resistencia pasiva, es previsible esperar reacciones de rechazo y enfrentamiento. "El capitalismo también seguirá dando bandazos, 
pero la ideología del laissez-faire probablemente se desvanecerá cuando los capitalistas descubran la serie de perturbaciones que el mercado sin trabas no puede resolver o incluso agravar. El capitalismo salvaje, con salarios bajos, jomada larga y trabajadores explotados, provoca el resentimiento social, resucita la guerra de clases y da nueva vida al marxismo. Para avanzar por senderos constructivos, el capitalismo debe subordinar los planes y beneficios a corto plazo a necesidades sociales de largo plazo, como las inversiones en educación, investigación y desarrollo, protección del medio ambiente, ampliación de la sanidad, rehabilitación de infraestructuras y recuperación de las ciudades. No es probable que los capitalistas lo hagan por sí mismos. Las perspectivas a largo plazo exigen una dirección pública"...

..."En el mundo, en general, $i$ podrá someterse el capitalismo, una vez sueltas las amarras nacionales, a responsabilidades sociales? ¿Adquirirán las instituciones internacionales autoridad para imponer, por ejemplo, una Comisión de Valores mundial?... La democracia en el siglo XXI debe entendérselas con las presiones de la raza, la tecnología y el capilalismo, $y$ hacer frente a las frustraciones y ansias espirituales generadas en el vasto anonimalo de la sociedad global. La gran fortaleza de la democracia es su capacidad de autorreforma. Para ello son esenciales un diagnóstico y una guía inteligentes. Quizás ninguna forma de gobiemo - dijo el historiador y diplomático lord Bryce - necesita tanto como la democracia de grandes dirigentes" 11 .

Con estas valiosas reflexiones de un asesor presidencial de Estados Unidos confimamos dos hipótesis de trabajo: el neoliberalismo necesita someterse a un proceso de autocrítica. Por una parte, la globalización es la fase superior del centralismo mercantil, que ya comienza a generar fuerzas centrífugas nacionalistas e incluso fundamentalistas. El neoliberalismo sustituye la planificación autoritaria estatal por la planificación omnipresente del mercado, que ahoga otras inversiones productivas y otros reclamos sociales. Estamos frente a dos modelos, hermanos gemelos de distinto padre, pero la misma madre, la misma historia antidemocrática. El neoliberalismo vuelve a generar, en clave mayor, los terrores de la proletarización y del darwinismo social, típicos en el liberalismo decimonónico. El neoliberalismo es más de lo mismo. Por lo tanto, el siglo XXI se presenta no como el fin de la historia, sino como el inicio de una historia impredecible, generadora de crisis, enfrentamientos, crecientes perturbaciones nacionales $y$, por supuesto, la gestación de nuevos modelos económico sociales.

\section{6. ¿El fin de la "edad de oro"?}

A medida que cerramos el presente siglo, desde varios países de Europa emerge la reflexión crítica en razón de las desigualdades acrecentadas por el reino de los mercados, la disociación económica generada por la especulación 
financiera y las crisis bancarias y bursátiles gestadas en los países del Sudeste asiático, que servían de propaganda del pensamiento neoliberal. Ahora ya no se puede culpar a los controles del Estado de ser el origen de estos pánicos mundiales, de estos desequilibrios económicos y sobre todo de la creciente disociación social.

Los tílulos de estos acápites han sido prestados de un reciente artículo escrito por Alain Tourrairke, director del Instituto de Estudios Superiores de París. Por las mismas rechas, el Instituto de Estudios Estratégicos de Londres comenta las crisis bursátiles del Sudeste asiático, con cierre definitivo de numerosas firmas bancarias peligrosamente endeudadas, fusiones de otras instituciones y voluminosas inyecciones de los gobiemos y del Fondo Monetario Intemacional para calmar los pánicos de las bolsas de valores. Estos cierres han generado el despido o cese del trabajo de miles de calificados empleados bancarios, que se suman al desempleo de los trabajadores manuales despedidos por las empresas productoras. Todo ello genera inquietud y descontento en estos países presentados como modelos económicos. El instiluto londinense se pregunta: “ $i$ El final de la "edad de oro?".

Ralf Dahrendorf, decano del College Oxford, subraya la disociación entre empresas y mercados de valores, entre economías reales y la realidad virtual de los mercados financieros y sus operaciones: "Una lección asiática". R. Dahrendorf había escrito en 1995 un opúsculo titulado: "La cuadratura del círculo", analizando -sobre ejemplos nacionales - las necesarias combinaciones entre el bienestar económico, la cohesión social y la democracia. Utilizando este título Joaquín Estefanía describe cómo el neoliberalismo no ha logrado sino que ha disociado esta necesaria combinación'12.

Integrando estos autores percibimos que, junto con una crítica del neoliberalismo por sus efectos en la desintegración social, se proponen avanzar hacia los controles estatales e internacionales, motivados por el descontento, la inquietud y la protesta que se hace oír de nuevo. Sin agregar ningún comentario podemos intercalar algunos de sus párrafos, que nos dan una visión más completa de este reino del mercado. Comenzamos por el inicio de la presente crisis. "Es al menos sorprendente que en la crisis económica política de algunos países de los denominados "tigres asiáticos", que comenzó en pleno verano y aún persiste, nadie —de sus antiguos entusiastas - haya salido a defender el modelo. Y sin embargo, los "ligres asiáticos" han sido un factor fundamental de la propaganda del pensamiento neoliberal durante bastante tiempo; su enome potencial de crecimiento, la agresividad comercial de los mismos, la rápida acumulación originaria de capital, la libertad de precios, un peculiar sistema educativo, etcélera, eran puestos por encima de olras contradicciones ocultas hasla ahora: son sistemas mecidos por el Estado a través de ayudas, subvenciones, tipos de cambio administrativos, estímulos a las ventas y un proteccionismo ofensivo; el Estado ha tenido el cuidado de proteger a determinadas empresas o sectores productivos 
para discriminarlos positivamente mediante apoyos a la exportación o restricciones a las importaciones. Pero ante todo, este "modelo asiático" ha despreciado otros asuntos de primera magnitud que no figuraban en la agenda de prioridades de sus hagiógrafos: la cohesión social y las libertades políticas clásicas para sus ciudadanos: no permiten la disidencia..." (Estefanía J.)

"La amenaza a la política de libre mercado en toda la región es bien real. Sin un final a la vista para un círculo vicioso de monedas a la baja, tipos de interés internos en aumento, débiles perspectivas de crecimiento y bolsas que se desmoronan, seguramente se manifestarán consecuencias políticas y estratégicas a largo plazo. Ya se dan diversos efectos: tensión social, inestabilidad políica, reconocimiento cada vez mayor de la fortaleza económica de Japón y cooperación financiera más esirecha en la zona... El rápido crecimiento ha creado y ocultado las tensiones sociales. Pese a enormes logros en la mitigación de la pobreza, para los habitantes de la zona son patentes profundas desigualdades. Existe un amplio resentimiento frente al "abismo de riqueza" entre una minoría plutocrática y los desfavorecidos.

Hasta cierto punto, el hecho de que a todo el mundo le fuera mejor suavizó estas tensiones. Pero el temor ante explosiones de ira popular ha hecho que se haya dado prioridad a los altos índices de crecimiento, a costa, a veces, de la racionalidad. Durante más de un año Indonesia ha experimentado disturbios que a menudo toman la forma de pogromos étnicos o religiosos, pero cuyas raíces están más bien en las desigualdades sociales. Tailandia, el país más desigual, se enfrenta ahora a la posibilidad de protestas protagonizadas por miles de obreros que perderán sus empleos. El riesgo más grande de inestabilidad se da también en Tailandia. El desplome ha coincidido con los intentos de reforma constitucional para erradicar la corrupción, a la cual se considera el principal molivo de malestar “. (Instituto de Estudios Estratégicos de Londres). En este artículo se señala que los nuevos ministros de Asuntos Exteriores de la Asociación de Naciones del Sureste (ASEAN) firmaron un comunicado el 25 de julio pasado, acusando a especuladores occidentales de "esfuerzos bien coordinados para desestabilizar las divisas de la ASEAN en su propio beneficio".

\subsection{El final de una ilusión}

Si del área del Sudeste asiático pasamos a Europa y a una visión más global del neoliberalismo, escuchamos a Alain Tourraine, en su artículo: «El final de una ilusión». "La época de las ilusiones se termina. El sueño de un mundo unificado por los mercados y que se proyecta hacia la prosperidad y la liberlad se ha rolo en pedazos. Las desigualdades y la precariedad se han acrecentado por el reinado de los mercados y provocan reacciones sociales y políticas en aumento. Paralelamente se asiste a una mulliplicación de las crisis financieras que resulta 
cada más difícil atribuir al control estatal de la economía. Entre los liberales radicales, que se vuelven cada vez más apremiantes, y los que instan a una nueva socialdemocracia la distancia se hace tan grande que es difícil ver de qué forma se podrá llegar a compromisos...

Esto hace indispensable acelerar nuestra salida teórica y práctica de la transición liberal en la que estamos inmersos desde hace 20 años, porque es preciso no dejar que aumente más aún la distancia entre la lógica financiera y las demandas sociales, distancia que amenaza el buen funcionamiento de la economía misma. Desde hace muchos años no se habla más que de racionalidad económica y de progreso técnico, y también de la necesidad de liberar la economía de las absurdas intervenciones del Estado. $Y$ he aquí que se descubre la irresponsabilidad, la vanidad o la corrupción de muchos de los dueños de las empresas y de los bancos más dinámicos, y que el discurso convenido sobre el milagro japonés se agota después de diez años de estancamiento de este país y que se pone de manifiesto el endeudamiento más que excesivo de las grandes empresas coreanas. No se trata de cuestionar de nuevo la apertura mundial de las economías, pero hay que buscar el modo de restablecer un cierto control social y político de la economía". (Alain Tourraine.)

"En los últimos años hemos experimentado una extraordinaria disociación entre empresas y mercados de valores o, en términos más generales, entre economías reales (incluidos los ahorros reales de la gente real) y la realidad virtual de los mercados financieros y sus operaciones... Esto no quiere decir que el movimiento de acciones y bonos sea impredecible. Pero sí quiere decir que la economía real ofrece solamente una ayuda limitada a la hora de hacer esa clase de predicciones. ¿Cómo se relacionan, entonces, estos dos procesos disociados? La respuesta, en el sentido más general, es: a través de los bancos. Los bancos tienen una función fundamental en la economía global. Existen porque la economía real los necesita y los alimenta; pero operan cada vez más en el ciberespecio de las operaciones financieras. Por supuesto, al hacerlo quieren agradar a sus clientes. $\mathrm{Y}$ estos clientes pueden volverse avaros. Los fondos de pensiones necesitan cada vez más dinero, al igual que las aseguradoras. Las empresas del sector servicios también necesitan cada vez más dinero.

Para satisfacer estas demandas, las instituciones financieras han desarrollado instrumentos cada vez más sofisticados y misteriosos. El mundo de los derivados y las opciones escapan a todo sentido común. Quienes se mueven en él utilizan una extraña mezcla de matemáticas avanzadas e intuición. Cada vez es menos fácil evaluar el riesgo que implican estas operaciones... En el proceso se corre un grave peligro de que los bancos se extralimiten. Eslo es lo que ocurrió en en Sureste asiático. Esto es lo que vuelve a suceder en Japón. Las repercusiones se sufren en todo el mundo por razones directas e indireclas. Las instituciones financieras están interrelacionadas y, si fracasan, afectan a la economía real y, 
por consiguiente, a las fuerzas coyunturales de todas partes.

A menudo se dice que los mercados financieros han crecido más que las instituciones políticas de control. El dinero global elude los parlamentos nacionales. Un hombre como George Soros se ha servido de este hecho, pero también ha pedido normativas y regulaciones globales. Esto tiene sentido... El control se puede ejercer a nivel nacional, aunque posiblemente para ello se requiera la presión intemacional, ya sea por parte del presidente de Estados Unidos o por el Fondo Monetario Intemacional (FMI)... En Londres, los espectaculares casos de colapso han provocado un significativo endurecimiento de la supervisión que ahora lleva a cabo un organismo nuevo e independiente. El objetivo de lodo esto es hacer que los bancos vuelvan a la economía real y se mantengan en ella". (Ralf Dahrendor.)

"Pero, $i$ quién puede ejercer este control cuando se nos repite constantemente que los Estados nacionales han perdido su poder y se han vuelto impotentes frente a la mundialización de los mercados? Esta firmación exige dos respuestas. La primera es que esto es falso en gran medida. Cuanto más compleja y cambiante es una economía, más difícil es lograr un crecimiento duradero, y la importancia de esta idea proviene de que muestra hasta qué punto los equilibrios internos de una sociedad se han convertido en condiciones necesarias para el crecimiento de una economía. Estos equilibrios sociales no se mantienen espontáneamente: al contrario, la economía de mercado crea desequilibrios y fuerzas de acumulación y exclusión que amenazan a los equilibrios básicos de la sociedad. Estos, para ser restablecidos, requieren la intervención del Estado y de otros agentes propiamente políticos y sociales.

La segunda respuesta es que los centros políticos de decisión sólo pueden luchar contra ciertas consecuencias de la economía de mercado si son forzados a intervenir por demandas sociales organizadas que se expresan por la vía electoral, a través de los medios de comunicación y, más directamente aún, bajo la forma de movimientos sociales organizados. Desde hace algunos años vemos aumentar en Europa occidental el número de gobiemos de centro-izquierda. Actualmente, sólo Alemania y España permanecen alejadas de este modelo dominante. La misma tendencia se manifiesta en los grandes países de América Latina, como México, que ha elegido a Cárdenas para la alcaldía de la ciudad de México, o Argentina, donde la candidatura de Frepaso, partido de izquierda, ha oblenido la alcaldía de Buenos Aires, e incluso Chile, donde el candidato mejor situado para la próxima elección presidencial es el jele de un partido de izquierdas...

El descontento, la inquietud y la protesta se hacen oír de nuevo. ¿Cómo podía ser de otro modo cuando la parte del producto nacional que va a los asalariados ha disminuido masivamente - alrededor del 10 por ciento- tanto en Alemania como en Francia, y cuando el salario real de los trabajadores menos cualificados ha disminuido en Estados Unidos, aunque este país está experi- 
mentando éxitos económicos sin precedentes? Seguramente, el despertar de las opiniones públicas y de la acción política no son suficientes para despejar la amenaza de fractura de la vida económica. Es preciso que los principales gobiemos y las instizuciones financieras internacionales intervengan, algo que éstas últimas han comenzado a hacer, puesto que tanto el Banco Mundial como el Fondo Monetario Internacional o el Banco Internacional de Desarrollo sostienen hoy discursos muy diferentes de lo que se sabía de ellos hace por lo menos diez años.

Nadie puede desear que se ensanche el abismo que separa ya al mundo económico de los mundos político o cultural. Por tanto, es necesario hacer lo posible para que se forme una voluntad colectiva de poner fin al desarrollo sin freno del capilalismo, es decir, de la economía de mercado, mientras rechace todo control político y social de sus aclividades. Hay que restablecer el control de los medios económicos para las finalidades políticas y sociales... La tormenta se escucha casi por todas partes, excepto en Estados Unidos, y en todos los países, incluido Estados Unidos; aumenta el temor de una crisis económica grave que incrementará la pobreza, la desigualdad y la exclusión de una manera insoportable. El largo silencio de la época neoliberal debe terminar y el debate público sobre los fines y los medios de la economía debe revivir. No perdamos más tiempo". (Alain Tourraine.)

Este mosaico de citas y reflexiones de connotados pensadores europeos nos muestra que el neoliberalismo necesita iniciar un proceso de autocrítica, si desea prolongar su historia. Dado que en la presente fase de euforia esta hipótesis es poco probable, se hace necesario que desde fuera del modelo, y por lo menos a nivel nacional, apuremos el proceso de crítica y alternativas realistas, en nombre de los sectores excluidos por el sistema. Al fin y al cabo, nuestro país es un buen laboratorio para observar los contrastes entre el equilibrio de la teoría económica y los desequilibrios sociales; los contrastes entre los principios éticofilosóficos y los fracasos de los postulados económicos. En un período preelectoral conviene refrescar las conciencias para que la reconversión política económica cobre fuerza desde las bases.

\section{Hagamos nuestra autocrítica}

La caída del muro de Berlín (1989) y la firma de la extinción de la Unión de Repúblicas Socialistas Soviélicas (1991) empalman con la subida al poder de un partido y de un gobierno que, por ocho años, cree y obedece las nomnas en boga del neoliberalismo político y económico. El plan de desarrollo económico y social, 1989-1994, enunciaba en su introducción los cinco principios filosóficos y los cuatro postulados económicos que sustentarían una sociedad libre. Estas bases doctrinarias estaban literalmente calcadas de una publicción de FUSADES: 
"Hacia una economía de mercado; bases para una nueva estrategia de desartollo económico y social" (Mayo de 1989). Ellas siguen inspirando al actual gobierno. Traslado estos lineamientos en forma casi literal.

\subsection{Los principios de una sociedad libre}

Una sociedad que quiere ser libre en el plan económico, político y en el orden de los valores y costumbres tradicionales debe apoyarse en los principios siguientes:

1) El hombre es el fin de toda la sociedad...

2) La libertad es la base del progreso humano...

3) La igualdad ante la ley es la garantía de la paz social...

4) La justicia garantiza a cada quien lo que le corrresponde...

5) El Estado desempeña un papel subsidiario...

Estos principios filosóficos requieren un mecanismo de organización y funcionamiento que haga posible el logro de una sociedad libre. A este fin sirven los cuatro postulados económicos:

1) La propiedad privada es condición necesaria para la eficiencia de la producción.

2) El mercado libre asegura la mejor asignación de los recursos.

3) La competencia garantiza el funcionamiento del mercado.

4) El Estado tiene un papel subsidiario.

Es claro que los principios filosóficos y los postulados económicos se inspiran en la ley del péndulo o "ley de lo contrario". Caída del muro de Berlín, descomposición de la URRS, fin de un gobierno demócrata acusado de atenazar la libertad económica y un adversario en la guerra civil, con el cual se pudiera llegar a firmar unos acuerdos de paz, pero nunca un pacto económico; el modelo económico no era punto de agenda por discutir. Mundialmente campeaba una ideología y había que entonar las notas del "fin de la historia". Cuando se publicó este plan de desarrollo 1989-1994, hacíamos unos primeros comentarios a sus principios y postulados, comentarios que todavía tienen el mismo valor desde la perspectiva de ocho años de implantado el modelol3.

\subsection{Los principios ético filosóficos}

¿Qué realismo histórico tienen ahora estos principios y postulados, que se repiten como un catecismo económico? Las bases doctrinarias ofrecen, nominalmente, una sumaloria de valores sociales: el hombre y el progreso humano, la 
libertad, la justicia, la igualdad y la paz social. Sin embargo, el primero y gran cuestionamiento de la autocrítica es analizar si los principios ético filosóficos son los que impregnan y determinan la aplicación de los postulados económicos, o son estos postulados, este modelo de mercado quien determina el significado real de aquellos principios. Lo cierto es que nos vamos a encontrar con otro dogma, que exige una fe ciega, aunque no lo acomapañen las obras. El punto de partida es que hay que legitimar el modelo de mercado, puesto que su contrario fracasó históricamente. Hay que legitimar el modelo, hay que justificarlo ética e incluso teológicamente frente a claras consecuencias antisociales o estructuras de pecado; y junto con la fe hay que crear la esperanza de que el "rebalse" se realizará oportunamente. Hay autores que se sienten llamados a ser los teólogos del capitalismo, verdaderos artislas en retorcer los textos del antiguo y nuevo testamento $(E C A, 1996$, pp. 72-73), de suerte que se permite hacer el mal sin remordimiento de conciencia.

Es necesario leer los principios élicofilosóficos desde el funcionamiento real del modelo económico. Aplicamos este ejercicio histórico-mental al llamado Eslado social de bienestar, que inspiró las economías concertadas de Europa occidental, luego de la segunda guerra mundial. El Estado social de bienestar actualizaba las consignas de libertad, igualdad y fraternidad-solidaridad, de suerte que el modelo de administración económica las convirtiera en liberlad-real, igualdad-real y verdadera solidaridad en la distribución y participación de los derechos económicosociales. El Estado era fundamentalmente un creador de valores 14 . En dicho comentario se contraponían los significados o traducciones tan distintas de libertad, justicia e igualdad en un Estado social y en un modelo neoliberal. La consigna de fratemidad-solidaridad no aparece en el diccionario neoliberal; esto explica que en países europeos se desee reacomodar el Estado social de bienestar.

\subsection{Lectura de los postulados económicos}

Puesto que nuestros principios ético filosóficos eran y aún son un simple adorno para legitimar los postulados económicos, vale la pena centrarse en estos últimos. Lo primero sería aclarar la semántica de sus enunciados. El primer postulado ya viene sobrecargado de ideología: "La propiedad privada es condición necesaria para la eficiencia de la producción". Este postulado afima taxativamente que la propiedad y la administración pública son genéticamente ineficientes. Por lo tanto se justifican, de entrada, la privatización de los servicios públicos y la marcha atrás de las nacionalizaciones decretadas. Tampoco es eficiente la propiedad cooperativa; por lo tanto, habrá que reformar la reforma agraria. Quedan fuera del radar económico los modos de propiedad mixta, controles directos e indirectos en manos del Estado, quien debe plegarse a un papel subsidiario. 
Tampoco queda muy claro si la propiedad privada es una simple "condición necesaria", un medio para un fin, o más bien es el fin de todos los medios. Lo fundamental es que este postulado ha tenido sólo dos fallos históricos. El primero es que la propiedad privada, en nuestro caso, es muy limitada y concentrada tanto del lado de la oferta como de la demanda; por lo tanto, falla la "condición necesaria" para la eficiencia de la producción. El segundo fallo histórico es que - pese a lo anterior- ha habido bastante propiedad privada y ésta no se ha tipificado por la "eficiencia de la producción". Esto es algo patente, como se verá enseguida. Por ello deducimos que el primer postulado es más dogmático que histórico.

"El mercado libre asegura la mejor asignación de los recursos". Llama la atención el tono lajante de este postulado cuando, incluso, los texlos clásicos del "Norte" señalan serias imperfecciones del libre mercado, que se recomienda sean controladas o corregidas por el Eslado: el ciclo económico, los bienes públicos, las externalidades o deseconomías sociales, la in [ormación al consumidor, los monopolios-oligopolios, la distribución de la renta y bienes preferentes... (Fischer S., Dornbusch R., Schmalensee R., pp. 78-87.)

Otro defecto más grave es la afirmación etérea del postulado. Si se habla del mercado es necesario aplicar el término a la realidad de nuestro mercado nacional, que tiene muy poco de libre, en razón de una serie de coyunturas históricas antes mencionadas: la estanflación, el creciente deterioro ecológico (5 por ciento del Producto Interno Bruto), el crecimiento con desempleo y desigualdad, la terciarización económica alimentada por el sesgo del crédito bancario, el notorio rezago tecnológico, el agotamiento de los nichos productivos y la inversión especulativa en el mercado financiero... Estas realidades explican simultáneamente la poca eficiencia de la producción y niegan la mejor asignación de los recursos. Con estos postulados dogmáticos lo único que se está afirmando y firmando es nuestra rendición ante el mercado internacional. Se está pasando de una economía basada en el trabajo y la producción a una economía de la importación. Los principios filosóficos quedan en el olvido.

\subsection{Mercado sí, pero no...}

Al mismo tiempo que se entona un himno al mercado, los hechos reales de la presenle y pasadas décadas demuestran las resistencias y la inoperancia frente a las exigencias del mercado. Dos texlos complementarios ilustran la situación. "Aspecto de singular importancia es cómo superar el patrón de comportamiento tradicional del sector empresarial, que cree en el principio del menor esfuerzo tecnológico. El proteccionismo excesivo de varios decenios provocó que ésle eludiera correr riesgos, en particular, los asociados a la innovación tecnológica. Muchos empresarios se han acostumbrado a no competir con mayor calidad y 
precio; prefieren hacerlo con publicidad, acceso a crédito preferencial y la obtención de subsidios del gobiemo, o sea, se habituaron a formas de competencia que exigen poco o ningún esfuerzo tecnológico, práctica que debe erradicarse para ser más competitivos" (ECA, 1997, p. 546).

Dos meses antes, una editorial adelantaba similar crítica. "El sector privado salvadoreño ha dado muestras de no estar dispuesto ni preparado para competir en una economía de mercado libre. Por un lado, reclama sus libertades pero, por otro lado, se niega a invertir si no cuenta con la protección del Estado o si éste no le otorga subvenciones y privilegios. En la práctica, no acepla una de las reglas fundamentales del mercado libre. En el otro extremo, el gobierno salvadoreño se encuentra atrapado entre las afirmaciones de su credo neoliberal y sus lealtades con el capital nacional, el cual espera de él protección y privilegios. El sector privado teme a la libre competencia y el gobiemo se siente naturalmente inclinado a protegerlo de sus vaivenes. Por lo tanto, en vistas a poner en marcha la estrategia de la competitividad, el sector privado debe cambiar su mentalidad y acomodar su conducta a los dictámenes de la competencia, y el gobiemo necesita romper sus alianzas de viejo cuño con el capital. La distinción estricta entre lo privado y lo público todavía no ha sido asimilada en El Salvador como una condición indispensable de la competitividad" (ECA, 1997, p. 374).

Leídos estos párrafos, el tercer postulado económico califica con baja nota a nuestro sector privado: "La competencia garantiza el funcionamiento del mercado". Por su parte, el cuarto postulado se aplica en forma restringida: "El Estado tiene un papel subsidiario". En razón de la débil eficiencia y competitividad del sector privado es este sector quien más reclama, a su favor, el papel subsidiario del Estado.

Llegamos a la conclusión de que no ha habido vasos comunicantes entre los principios filosóficos y los postulados económicos: el hombre y el progreso humano, la justicia, la igualdad y la paz social no aparecen como el "rebalse" de los postulados económicos. Tampoco los postulados económicos se han traducido en eficiencia productiva, mejor asignación de los recursos y competitividad económica. Tal vez por esta razón no se han vuelto a reeditar literalmente estos principios y postulados, porque aparecen como un arco iris por encima de la realidad.

\subsection{Inconsistencia de la política económica}

La impresión generalizada es que el actual gobierno muestra una "inconsistencia en la definición de la política económica": "Esto es indiscutible, pues al inicio del segundo gobiemo de ARENA se dijo que El Salvador se convertiría en un gran país maquilador; a los pocos meses nadie habló sobre eso y se comenzó a promover la dolarización de la economía, proyecto que fue 
abandonado sin conocer explicaciones; luego se dispuso liquidar la planificación global y enfatizar las políticas sectoriales. Esta acción también fue neulralizada y el propio Ministro de Hacienda en forma insólita declaró que las políticas sectoriales estaban "pasadas de moda" y que no era productivo promoverlas. Así, se llegó a la novedad de impulsar los clusters, o sea, las alianzas competitivas que la mayoria de productores desconoce... (ECA, 1997, pp. 538-539).

Un derivado de la inconsistencia en la definición de la política económica es la formulación de un nuevo dogma sobre la solidez, sanidad de nuestra economía y de su crecimiento, atribuyendo a causas coyunturales extemas la recesión y fallas estructurales internas. Año con año se nos hace escuchar los mismos estribillos: el Producto Interno Bruto, las Remesas Internacionales Netas, la inflación y los déficits menguantes, el ser sujetos de crédito y de prestigio internacional. " ¿De qué sirve que la inflación se neutralice, si la mitad de la población no tiene empleo estable, ni obtiene ingresos que alcancen a penas los límites de la supervivencia?". ( $E C A, 1997$, p. 536). Ni las encuestas de opinión pública, ni los resultados de las elecciones nacionales se dejan convencer por esta ilusoria publicidad. Tampoco se dan por convencidas las instituciones que han presentado programas económicos altemativos (ANEP, FUNDE, CPDN, FMNL...) para dar un nuevo rumbo y dirección a la actual economía. Hay crítica, hay preocupación y lal vez un asomo de autocrítica.

Leyendo, con atención, los discursos presidenciales, incluso el presidente, algo proclive a lo sorpresivo y sorprendente, no se muestra satisfecho con la evolución económica. Luego de haber derruido el Ministerio de Planificación, en sus discursos del 1 de mayo y 1 de junio de 1997, da la impresión de querer "reconstruirlo en tres días". El presidente anuncia: "la formulación de un Plan de Desarrollo Nacional, con una visión de mediano y largo plazo, que nos lleve al desarrollo y genere estabilidad y confianza" (El Diario de Hoy, 1 de mayo de 1997). "Necesitamos tener una visión de largo plazo para dar estabilidad y continuidad al país, más allá de los períodos de gobierno, a fin de convertir a nuestro país en un lugar atractivo para la inversión y generación de empleo, que eleven el bienestar y calidad de vida de la población" (ítem, 1 de junio, 1997).

Estos lextos son valiosos por lo que dicen y porque al menos, literalmente, hay algo de autocrítica. Literalmente se reconocen serios fallos en la conducción económica: no hay un plan nacional de desarrollo, a menos que se adopte el plan trienal del Banco Mundial (ECA, 1997, pp. 365...). No hay una visión de mediano y largo plazo, ni estabilidad, ni confianza, y se reconoce el desafío del empleo, del bienestar social y de la calidad de vida de la población. Entre líneas se afirma que el próximo gobierno sí debiera guiarse con un plan de desarrollo. En eslos discursos, ¿hay una autocrítica real o sólo verbal? 


\section{6. ¿Se autocriticará nuestro capitalismo?}

Sea cual sea la sinceridad de estas palabras, dan lugar a trasladar de nuevo las advertencias de A. Schlesinger: "El capitalismo seguirá dando bandazos, pero la ideología del laissez-faire probablemente se desvanecerá cuando los capitalistas descubran la serie de perturbaciones que el mercado sin trabas no puede resolver o incluso agravar. El capitalismo salvaje, con salarios bajos, jomada larga y trabajadores explotados, provoca el resentimiento social, resucita la guerra de clases y da nueva vida al marxismo. Para avanzar por senderos constructivos, el capitalismo debe subordinar los planes y beneficios a corto plazo a necesidades sociales de largo plazo, como las inversiones en educación, investigación y desarrollo, protección del medio ambiente, ampliación de la sanidad, rehabilitación de infraestructuras y recuperación de las ciudades. No es probable que los capitalistas lo hagan por sí mismos. Las perspectivas a largo plazo exigen una dirección pública".

Desde Francia, Alain Tourraine nos decía: "Nadie puede desear que se ensanche el abismo que separa ya el mundo económico de los mundos político o cultural. Por tanto, es necesario hacer lo posible para que se forme una voluntad colectiva de poner fin al desarrollo sin freno del capitalismo, es decir, de la economía de mercado, mientras rechace todo control político y social de sus actividades. Hay que restablecer el control de los medios económicos para las finalidades políticas y sociales"...

Estas palabras de A. Schlesinger y A. Tourraine (Atlántico de por medio) son, ante todo, una seria advertencia a nuestro gobierno y a los electores del gobiemo. En 1999 hay que tomar serias decisiones al respecto. Pero estas decisiones carecerán de base sólida si a lo largo de 1998 no concretizamos, entre lodos, programas económicos más realistas y más sociales. Un plan de desarrollo arranca del descubrir y describir la verdad económica, sin disimularla; un plan de desarrollo se prepara en forma dialogada y concertada entre la administración pública y los representantes, empresariales y laborales, de los sectores productivos. ¿Será suficiente un año para que los de arriba y los de abajo avancemos en este sentido? Seguramente, no. Y el nuevo siglo-milenio se iniciará con similares tensiones económicas, políticas y sociales con que se inauguró el presente siglo XX. También nuestro futuro es impredecible.

\section{Nolas}

1. Schlesinger A. “¿Tiene futuro la democracia?, Política exterior, No 60 , noviembrediciembrc, 1997, pp. 131-132.

2. Ibidem, p. 133.

3. Ibidem, pp. 133-134.

4. Ibidem, pp. 134-135.

5. Ibisate F.J. “ ¿Es cl crecimicnto la locomolora de nucstra cconomía?, ECA, 1997, No 587, pp. 799-817. 
6. Schlesinger A. liem, pp. 135-136.

7. Ibisale F.J. “ ¿Socialismos en hibernación?, ECA, No 573-574, 1996, pp. 583.

8. Schlesinger A. Item, p. 136.

9. Ibisate F.J. “¿Es élico canonizar la globalización?, ECA, No 583, 1997, pp. 383402. Sínodo Americano: "Mensaje de la Asamblea Especial para América", Orientación, No 5011, 21 de diciembre 1997, pp. 2 y 15.

10. Schlesinger A. Item, p. 137.

11. Ibidem, pp. 140-143.

12. Tournaine A. "El final de una ilusión", El País, 10 diciembre, 1997. Instituto de Estudios Estratégicos de Londres. "¿El fin de la edad de oro?, El Pals, noviembre, 1997. Dahrendorf R. "Una lección asiática”, EI Pais, diciembre, 1997.

Estefanía J. "La cuadratura del círculo", El Pals, noviembre,1997.

13. Ibisate F.J. "Un programa de ajuste estructural: una herencia dificil", Realidad Económico-Social, No 15, 1990, pp. 215-239.

14. Ibisate F.J. "Propuestas de bienestar icon Estado de bienestar?", ECA, No 576, 1996, pp. 865-887. 